\section{- pavor \\ da carne: \\ riscos da \\ pureza \\ e do sacrifício no corpo-imagem contemporâneo}

\section{RESUMO}

$\mathrm{O}$ artigo retrata 0 atual enaltecimento do corpo humano. Último grande refúgio da subjetividade, o corpo é obstinadamente submetido a toda uma série de estratégias de design epidérmico que apontam para o cultivo das "boas aparências", numa era na qual a visibilidade e o reconhecimento no olhar alheio são fundamentais na definição do que cada um é.

\section{ABSTRACT}

This text analyses the glorification of the human body, the last grand refuge of our subjectivity nowadays. The body has to be made almost perfect in its appearance by epidermic design because in the present era one is defined by the visibility and recognition of the gaze of the other

\section{- Corpo (Body) \\ - Aparência (Appearance) \\ - Mídia (Media)}

palaVRAS-chaVe (Key WORDS)

\section{Paula Sibilia UFRJ}

\begin{abstract}
- Georgiana, jamais pensaste na possibilidade de apagar essa mancha da tua bochecha?

... Saíste das mãos da Natureza tão próxima da perfeição que o menor defeito... escandaliza-me, por parecer um sinal visível da imperfeição terrena.

... Vendo-a tão perfeita em todo o resto, porém, aquele único defeito pareceu-lhe cada vez mais intolerável à medida que passavam os dias de sua vida em comum. Era o estigma fatal da humanidade, que a Natureza imprime sob uma ou outra forma em todos seus produtos, ora para que se entenda que são temporais e finitos, ora para indicar que a sua perfeição exigirá esforço e dor.
\end{abstract}

A mancha Athaniel Hauth thom

O MUNDO ATUAL OSTENTA, entre muitos outros, um paradoxo que pode parecer desconcertante. Por um lado, percebe-se um evidente enaltecimento do corpo humano. Último grande refúgio da subjetividade, o corpo é obstinadamente submetido a toda uma série de estratégias de design epidérmico que apontam para o cultivo das "boas aparências", numa era na qual a visibilidade e o reconhecimento no olhar alheio são fundamentais na definição do que cada um é. Ao mesmo tempo, por outro lado - e é aqui que o mencionado paradoxo se ergue, desafiando o pensamento para além das evidências - o corpo é desprezado com uma violência inédita.

É precisamente a condição carnal e material do corpo humano, a sua viscosidade orgânica e biológica, que se tornou o alvo de uma rejeição ativa nas sociedades ocidentais dos inícios do século XXI - um tipo de formação social que assiste pela primeira vez na história a um crescimento desmesurado da obesidade em todo o mundo, e a uma curiosa conseqüência dessa expansão: a lipofobia, um horror cada vez mais visceral aos tecidos adiposos que naturalmente conformam o corpo humano. Assim, enquanto o capitalismo dos excessos e da opulência, do marketing hedonista e da gula consumista, sobrepõe-se à velha economia da escassez, o costumeiro fantasma da fome - um eterno companheiro indesejável da humanidade - é desbancado por um recém-chegado: o temível fantasma da gordura. ${ }^{2}$ Cada vez mais, a sombra inchada desse espectro apavorante agita os mercados e desvela não apenas os cientistas em 
seus laboratórios (que desejam descobrir a panacéia para exorcizá-lo), mas também e sobretudo a ansiosa iniciativa empresarial (que desvaira por comercializar tal poção mágica) e os igualmente ansiosos consumidores (que desesperadamente querem comprá-la para vê-la agindo em seus próprios corpos).

A despeito de todas essas novidades decorrentes dos excessos da festa consumista, nos cantos mais esquecidos do planeta não deixa de aumentar a porção da humanidade que cotidianamente morre de fome: 24 mil pessoas por dia, 11 crianças por minuto. Longe dos holofotes e sem alardes midiáticos, obscuramente, o problema da fome tem crescido nos últimos anos, afetando de maneira direta um quarto da população mundial. ${ }^{3}$ Mas não adianta apelar ao catastrofismo das cifras, pois apesar de sua brutal consistência, tais dados se perdem na maré da informação cotidiana e seus efeitos potenciais são anestesiados no esquecimento prático. Hoje, então, o problema da obesidade está sufocando o velho problema da fome, e a procura de soluções - tanto estritamente tecnológicas como biopolíticas - visa quase exclusivamente a resolver a primeira questão, relegando a segunda à letra pequena do contrato social global. ${ }^{4}$

Em meio a um mundo esfomeado que incita à voracidade constante, portanto, os cidadãos-consumidores que monopolizam o drama contemporâneo colocam em cena toda uma série de táticas e estratégias de estilização corporal, visando a esconjurar o fantasma da gordura. Essas práticas, que invadiram o cotidiano nos últimos anos e estão se tornando uma verdadeira obsessão para boa parte da humanidade, procuram concretizar um sonho que ainda continua parecendo impossível: o de dominar essa carnalidade inefável e incômoda, sempre imperfeita, flácida, gordurosa, fatalmente submetida à dinâmica abjeta das secreções e da decomposição orgânica. Almeja-se, nessa luta desigual contra a teimosia da carne, atingir uma virtualização imagética tão descarnada como descarnante. Alguns ingredientes desses sonhos etéreos merecem ser investigados, levando em conta sua gênese histórica e sua raiz nitidamente política, pois tais tendências respondem às severas exigências de um determinado projeto de sociedade, atualmente vigente em vastos setores do nosso planeta globalizado.

As novas práticas bio-ascéticas dos regimes alimentares, das cirurgias plásticas e dos exercícios físicos se expandem velozmente na procura do fitness - isto é, da árdua adequação dos corpos humanos a um ideal exalado pelas imagens midiáticas cada vez mais onipresentes e tirânicas, impondo por toda parte um modelo corporal hegemônico, e disseminando uma rejeição feroz diante de qualquer alternativa que se atreva a questioná-lo. Constantemente, os indivíduos são interpelados por esses discursos midiáticos e por essa aluvião de imagens que ensinam as formas e as leis do "corpo bom", e ao mesmo tempo são informados sobre todos os riscos inerentes aos "estilos de vida" que podem afastá-los perigosamente desse ideal. O mero fato de viver - isto é, o acaso de ser um corpo vivo, orgânico e material - já é uma enorme desvantagem nessa missão, pois quase tudo conduz à fatal deterioração física. Comer, por exemplo, mesmo que seja apenas "alimentos leves e saudáveis"; ou simplesmente estar no mundo enquanto o tempo transcorre e vai deixando suas abomináveis seqüelas na carne - tudo conduz, inexoravelmente, à degeneração.

Ainda assim, nos é dito que é possível prevenir o pior - ou, pelo menos, que seria possível demorar a sua fatídica chegada. Pois os riscos (ainda?) não podem ser eliminados de vez, só podem ser parcialmente controlados ou, no melhor dos casos, diminuídos, lançando mão de grandes doses de prudência e sacrifício, privações e sofrimentos. Ou seja, graças a uma boa gestão de si que envolva não apenas o indispensável autocontrole, mas também um bom conjunto de práticas bio-ascéticas. Basta, portanto - conforme nos é dito uma e outra vez - estarmos sempre alertas e informados sobre os riscos que corremos e sobre as diversas formas de contorná-los, para tomarmos as decisões adequadas e agirmos corretamen- 
te, a fim de manter sob controle os inevitáveis desbordes do nosso lastro demasiadamente carnal. Assim, a responsabilidade individual constitui a base de toda uma série de novas condenações morais, que têm o corpo como seu principal alvo e campo de ação.

Pureza e sacrifício são dois conceitos-chave nestes processos. Toda impureza orgânica será repelida e, para isso, impõe-se um amplo catálogo de rituais de um novo tipo de sacrifício da carne, que envolve o intenso investimento de três elementos dos mais prezados na cosmologia contemporânea: dor, tempo e dinheiro. Assim, junto com um certo neo-gnosticismo de inspiração digital, que pretende virtualizar o corpo humano ultrapassando os limites da sua materialidade orgânica, novas formas de ascetismo se desenvolvem, na procura de um corpo construído como uma imagem pura, um modelo insuflado pelo imaginário digital que permeia a nossa cultura. Isto é, um corpo-ícone desenhado para o consumo exclusivamente visual.

\section{Canto a๑ corpo "perfeito": ๑ espelh॰ convexo da subjetividade con- temporânea}

Se existe alguma possibilidade, por remota que ela for - prosseguiu Georgiana -, devemos tentar. Pouco importa o risco. O perigo não representa nada para mim; enquanto esta mancha odiosa me converter em causa de teu horror e tua repugnância, a vida... a vida é uma carga da qual me livraria com prazer. ${ }^{5}$

Todas as culturas possuem um certo ideal de "corpo belo", que dissemina seu cânone e propaga uma "normalização" da população em torno dessa proposta ideal. $\mathrm{Na}$ sociedade contemporânea, entretanto, tal modelo parece se impor de maneira cada vez mais opressiva e generalizada, investindo os corpos e as subjetividades com uma potência inédita. A força incomum desse imperativo na época atual decorre, sem dú- vida, da importância que vem ganhando o mercado das aparências. Cada vez mais, a subjetividade parece se ancorar na exterioridade da pele, nos sinais visíveis emitidos por um corpo que rivaliza constantemente pela captação dos olhares alheios em um mundo saturado de estímulos visuais.

Essa tendência reflete um certo esvaziamento da interioridade, no sentido de um espaço íntimo e privado localizado "dentro" de cada indivíduo; uma esfera "interior" que, ao longo da Modernidade, constituíra o eixo em torno do qual as subjetividades eram definidas - zelosamente alicerçadas e laboriosamente edificadas, nesse âmago fértil porém oculto nas próprias profundezas. ${ }^{6}$ Mas o apagamento desse magma interior que costumava dar consistência ao homo psychologicus está cedendo terreno a outras construções subjetivas. Assim, tendências exibicionistas e performáticas alimentam as novas modalidades de construção e consumo identitário, numa espetacularização do eu que visa à obtenção de um efeito: o reconhecimento nos olhos do outro e, sobretudo, o cobiçado fato de ser visto. Nesse contexto, a subjetividade é estruturada em função da superfície visível do corpo, que se torna um espaço de criação epidérmica e um campo propício para a expressão do que cada um é.

\section{Risco, prudência, segurança e respon- sabilidade individual na socieda- de dos excessos}

Minha nobre esposa, já tenho te injetado substâncias de tanta potência que o próximo passo seria modificar o teu organismo por completo. Só resta uma coisa para fazermos. Se falhar, estaremos perdidos... ${ }^{7}$

A imposição de um ideal de beleza corporal cada vez mais rígido implica, também, a propagação de novos tipos de condenação moral, que envolvem a acusação de negligência àqueles que não conseguem se enquadrar nesse padrão. Assim, os impe- 
rativos da prevenção e do fitness se tornam compulsórios, generalizando a obsessão pela saúde, pela juventude e pela beleza. Tais fenômenos parecem constituir novos vetores do biopoder, desenvolvidos na sociedade contemporânea a partir da privatização das biopolíticas (outrora estatais, e portanto públicas) e da disseminação da lógica empresarial em todos os âmbitos. Reformulando esses conceitos forjados por Michel Foucault em suas análises da sociedade industrial, hoje as políticas que modelam a vida não se dirigem aos cidadãos dos antigos Estados-Nação mas a outro tipo de "sujeitos livres": aqueles inseridos nos circuitos integrados do capitalismo pós-industrial. ${ }^{8}$

Nesse difícil contexto, é preciso planejar a própria vida como os empresários delineiam as estratégias de seus negócios: avaliando os riscos e fazendo as escolhas certas; ou seja, aquelas que visem a maximizar a "qualidade de vida". Em um mundo articulado pelas leis impiedosas do mercado universal, todos devem assumir seus papéis de consumidores e gestores de si, administrando seus capitais vitais para exibir um bom desempenho e um perfeito domínio de si. Os recursos pessoais e privados devem ser otimizados, gerenciando as opções de acordo com parâmetros de custo-benefício, performance e eficiência. Assim, a lógica da empresa se espalha por todo o corpo social.

A idéia de risco é especialmente relevante nesta nova configuração, pois denota várias transformações com relação à sociedade que se organizava em torno do capitalismo ancorado na indústria. Esse tipo de formação social, que vigorou ao longo do século XIX e teve seu auge na primeira metade do século $X X$, ainda era uma sociedade da escassez administrada por um Estado regulador cuja função primordial consistia na distribuição da riqueza. Tal é, reproduzida de maneira um tanto esquemática, a forma com que Ulrich Beck conceitua o Estado de bem-estar em seu livro já clássico sobre a Risk Society, no qual elucida uma série de mudanças relativamente recentes na lógica de funcionamento das sociedades ociden- tais. Com a progressiva satisfação das necessidades materiais e, de certo modo, com a virtual eliminação do problema da escassez, a partir dos avanços tecnocientíficos e dos conseqüentes excessos na produção de bens, emergiu um efeito colateral indesejado: teriam aumentado consideravelmente o número e a dimensão dos riscos e das ameaças, tanto em nível individual como global. O lado obscuro do crescimento das forças produtivas na modernização é, curiosamente, um incremento paralelo das forças destrutivas.

Assim, em decorrência de tais processos, nas últimas três décadas foi se configurando um novo perfil estatal, associado às tendências privatizantes do neoliberalismo. Nesta sociedade do risco, a função do Estado passa a ser a de garantir uma certa distribuição desses riscos entre os membros da população (envolvendo a prevenção e o controle), e não mais uma distribuição da riqueza escassa - tarefa que seria deixada, cada vez mais, em mãos do mercado e dos próprios indivíduos. Cabe acrescentar, aqui, um parêntese importante, pois é preciso adicionar a esse quadro a imposição de uma certa lógica vinculada ao consumo como um ingrediente fundamental da sociedade atual, que considera apenas certos segmentos da população e ignora - ou exclui - aqueles que ainda são atingidos pela velha (porém virulenta) lógica da escassez. ${ }^{9}$ Somente considerando esta importante ressalva é possível afirmar, junto com Beck, que hoje "o problema do sobrepeso ocupa o papel antes ocupado pela fome", ${ }^{10}$ como duas metáforas perfeitamente atinadas das fantasmagorias mais pregnantes, respectivamente, das sociedades da abundância e das sociedades da escassez.

Aparentados com os espectros obesos que se multiplicam sem cessar, esses riscos high-tech que hoje nos assombram também são fruto do excesso, pois não se trata mais dos clássicos perigos vinculados à escassez ou à precariedade que tradicionalmente vigoraram em todos os tempos e espaços do longo drama humano. Trata-se, 
portanto, pelo menos nesse sentido pontual, de um fenômeno radicalmente novo. E ainda há outra questão igualmente nova e inquietante: a fome, se for considerada um problema absoluto, é do tipo que poderia ser inteiramente resolvido: basta comer, e ela será saciada. Já o risco é um problema de outra natureza, pois por sua própria definição jamais poderá ser eliminado de vez. O risco é uma probabilidade; e como tal, em maior ou menor grau, ele sempre existirá. Essa variável do grau de incidência pode (e, cada vez mais, deve) ser calculada em cada circunstância particular; porém há uma verdadeira tragédia na base: o risco jamais poderá ser eliminado completamente. E ainda há outro elemento perturbador: mais uma vez, diferentemente de problemas como a fome (que afeta apenas a alguns e pode ser saciada), o risco afeta a todos os indivíduos - em menor ou menor grau, eis a questão. A conclusão é terrível: não há como fugir dele, e tampouco é possível esquivar a sua minuciosa lógica do cálculo, da negociação e da prevenção sem fim.

Contrariamente ao que ocorre com o exemplo da fome, só pode haver risco se for possível escolher entre várias opções disponíveis e, a partir daí, tomar decisões. Em total concordância com as regras básicas do ideário neoliberal, portanto, a responsabilidade é de cada indivíduo. Retomando o exemplo da obesidade e do sobrepeso como um risco que a todos pode afetar, cada um também pode optar por limitar (ou não) certos prazeres atuais a fim de evitar o sofrimento no futuro. Assim, a lógica da distribuição do bem-estar foi relegada aos indivíduos, pois com a crise do Estado benfeitor cada um deve cuidar de si. De acordo com seu novo perfil, agora o Estado só pode cuidar dos prudentes. ${ }^{11}$ Neste sentido, é sintomática a proposta do governo da Austrália de instituir um imposto especial para os obesos mórbidos - aqueles que excedem em mais de 50 quilos o peso considerado padrão - por eles onerarem o sistema público de saúde. ${ }^{12}$ A mensagem é clara: se a culpa é deles, então não cabe ao Estado se respon- sabilizar; são eles próprios que devem pagar por isso.

Em um mundo que consagra a prudência como um dos valores mais prezados e convenientes, não surpreende que a segurança se torne a grande demanda social e o único fim ainda legítimo da política, e que a incerteza e o pânico dominem as subjetividades mais enfraquecidas e vulneráveis, inscritas em um nível jamais vivenciado de individualismo, de "declínio do homem público" e de enorme descrédito com relação às possibilidades da ação política. ${ }^{13}$ Tornam-se incompreensíveis, neste quadro, os principais elementos da antiga "ética do guerreiro", bem como as conotações positivas que o ato de "se arriscar" poderia emanar. ${ }^{14}$ Ao contrário, a epopéia mesquinha da gestão de si é individualista, refratária aos coletivos e fortemente apolítica. Apresenta-se como mais uma torção da velha ética protestante, com seus tradicionais ascetismos e outros sacrifícios que residem na base do pathos burguês. ${ }^{15} \mathrm{~A}$ imagem que com mais força se evoca, porém, é a daquela medrosa toupeira que protagoniza uma das fábulas mais impressionantes de Franz Kafka: A construção. ${ }^{16}$ Em uma sociedade articulada pelos riscos e pelo pânico individual, é o futuro (possivelmente terrível) que determina e molda o presente (que, mesmo sendo morno ou medíocre, se quer imutável e eterno). Mas essa moldagem é exercida sob a forma da prevenção, da prudência e do medo, e não mais sob os ímpetos revolucionários da construção, dos desejos desmesurados (e portanto necessariamente arriscados e destemidos) ou até mesmo das antiquadas utopias.

\section{Sonhos anoréxicos contra • corpo abjeto: • arriscado fundamen- talismo da norma}

A mancha encarnada simboliza a inevitável férula da mortalidade sobre o lodo humano da mais alta e pura condição, que vê imposta uma familiaridade degradante com o mais baixo, $\mathrm{e}$ 
até mesmo com as bestas, a semelhança das quais sua forma visível volta ao pó. ${ }^{17}$

No contexto descrito nas páginas precedentes, parece lógico que os fumantes sejam estigmatizados por serem incapazes de cuidar da sua própria saúde - e por colocarem em risco, de maneira irresponsável, a saúde alheia. Do mesmo modo, os obesos são desprezados por demonstrarem uma incapacidade flagrante para administrarem a sua aparência com sucesso. $\mathrm{O}$ mesmo veredicto se aplica, cada vez mais, a qualquer pessoa cujo aspecto se distancie do modelo considerado "correto". Apesar da exacerbação do individualismo na sociedade contemporânea, e da ênfase na livre-escolha e na responsabilidade individual que alicerça a nossa risk society, observa-se uma moralização crescente das práticas corporais e uma evidente condenação moral a quem não se enquadrar no padrão culturalmente imposto.

Pois com a crise da "vida interior" e o deslocamento da identificação subjetiva para a exterioridade e para a visibilidade, hoje o caráter se torna externo. Cada um passa a ser aquilo que mostra de si. Cada vez mais, a marca identitária se fundamenta na aparência, nos sinais exteriores e visíveis emitidos por cada pessoa. O corpo se torna uma imagem a ser exibida; e essa imagem deve ser jovem, bela e magra. Assim, o sujeito excedido de peso é reprovado por não ser um bom gestor de si. Isso equivale a afirmar que se trata de alguém moralmente fraco, pois em um mundo comandado pelos ditados do mercado e no qual vigora a administração individual dos capitais vitais, o lema é evidente: "só é gordo quem quer". $\mathrm{E}$, como parece óbvio que ninguém poderia mesmo "querer" tal coisa no mundo contemporâneo, supõe-se que só estará excedido de peso quem não conseguir se autocontrolar - ou seja, quem for incapaz de não ser gordo, quem é negligente, ineficaz, fraco.

Tampouco surpreende, neste árduo contexto, que estejam se tornando endêmi- cas certas patologias relacionadas com as distorções da imagem corporal - dolências que outrora se apresentavam de maneira isolada e constituíam casos raros, mas nos últimos tempos estão se espalhando de forma alarmante. A anorexia, por exemplo, se alastra com a velocidade e a virulência de um vírus, sobretudo entre as adolescentes das classes médias e altas das grandes cidades do mundo ocidental, com especial incidência em certas áreas da América Latina. De acordo com estudos publicados nos últimos anos em periódicos como o Journal of Adolescent Health e o American Journal of Psychiatry, a anorexia nervosa é a terceira doença crônica mais freqüente entre as mulheres adolescentes - depois da obesidade (!) e da asma. Existe todo um leque de quadros anorexoides, em cujo extremo de gravidade figura a anorexia vera; neste caso, $90 \%$ das vítimas é de mulheres e apenas 10\% de homens. O quadro envolve uma busca tenaz da magreza e uma autovaloração excessivamente baseada no aspecto corporal. Em todos os casos, a eficácia conseguida no controle do próprio peso - visando à sua diminuição constante e sem fim - é o principal fator determinante da auto-estima.

Percebe-se, portanto, que a sintomatologia desses transtornos dismórficos - não apenas da anorexia, mas também de outras variantes como a bulimia, a vigorexia e a ortorexia $^{18}$ - parece denotar um tipo de adaptação compulsiva à norma. $\mathrm{O}$ que não deixa de constituir um certo paradoxo, numa sociedade que alardeia o triunfo definitivo da livre-escolha e do hedonismo, instando à negociação individual permanente entre os riscos e os benefícios de cada decisão, propondo desafios que são cada vez mais difíceis de concretizar: seja diferente e seja você mesmo. Mas tal paradoxo talvez possa ser desfeito, revelando os fios lógicos que o constituem.

Segundo a pesquisadora norte-americana Gail Weiss, a sociedade atual promove uma "rejeição corporal à corporeidade", uma vontade de transcender a materialidade orgânica do corpo. Tal tendência seria 
uma exacerbação de um fenômeno universal e de um mecanismo psicológico "normal" na construção da imagem do eu: a exclusão do abjeto. Isto é: algo "repulsivo" ligado à animalidade do corpo humano, às vísceras e à viscosidade orgânica - enfim, o pólo material do velho dualismo cartesiano, tradicionalmente desdenhado ao longo da história da metafísica ocidental por se associar à imanência contrapondo-se à transcendência imaterial da mente ou da alma. ${ }^{19}$

Esse elemento repulsivo, portanto, costuma ser expulso da unidade corporal simbolicamente construída a partir da experiência sempre fragmentária do corpo vivo e respeitando a norma culturalmente imposta. ${ }^{20}$

Embora o abjeto seja normalmente excluído das construções identitárias, ele permanece assediando nas sombras e constitui uma ameaça permanente de desestabilização para a unidade do eu. Os sujeitos "saudáveis", porém, habituam-se a negociar com tais pressões, e conseguem manter as fronteiras dentro de limites toleráveis para a unidade subjetiva. Já aqueles que sofrem de patologias vinculadas às distorções da imagem corporal, ao contrário, exprimiriam uma incapacidade de negociar entre a norma e a multiplicidade de imagens corporais decorrentes da experiência do corpo vivo, fomentando uma excessiva coerência da imagem corporal - uma entidade que habitualmente é fluida e instável. Essa rigidez e essa dura obstinação na coerência acabam dando à luz a subjetividades "fundamentalistas" da imagem do corpo ideal: aquele modelo que opera como uma norma na sociedade. A identidade se projeta nessa imagem especular (e cultural, portanto intersubjetiva), e adere a ela rigorosamente, a fim de obter o reconhecimento nos olhos dos outros. Na base de tais processos esconde-se um temor excessivo à fragmentação identitária - e, certamente, também à viscosidade orgânica do corpo; ou seja: ao abjeto que deve ser banido.

De acordo com esta perspectiva, então, hoje o desvio da norma não estaria encarna- do nas perversões sexuais - como apregoou longamente o saber psiquiátrico constituído no século XIX - mas na negligência, ou na incapacidade de manter o autocontrole com relação a certos itens específicos: alimentos "proibidos", cigarros, álcool, drogas, etc. Os sujeitos que hoje se desviam são, precisamente, aqueles que não cuidam de si, que não conseguem tratar e moldar seus corpos da forma "certa", demonstrando falhas na sua função de autogestores. Em síntese: aqueles que não conseguem cultivar estrategicamente a sua imagem pessoal e a sua reputação. Tratar-se-ia, portanto, de "seres abjetos", eventualmente excluídos até da própria categoria de sujeitos. De certo modo, tais criaturas estariam no limiar da humanidade, sempre ameaçadas de caírem no domínio das monstruosidades e das aberrações.

\section{Novos rifuais bio-ascéticos: o sacrifício da carne rumo ae ideal descar- nado}

Seu coração tremia, é verdade, mas Georgiana exultou ao pensar no nobre amor de Aylmer; um amor tão puro e elevado que somente aceitaria a perfeição, sem se resignar jamais (triste derrota) a uma condição mais terrena do que aquela que sempre sonhara. Compreendeu quão preferível era aquele sentimento a qualquer outro que pelo seu próprio bem suportasse, mais mesquinho, a imperfeição, e incorresse no delito de traição contra o amor sagrado, por degradar sua idéia perfeita a níveis de realidade. ${ }^{21}$

Paradoxalmente, em uma sociedade que alardeia os consumos hedonistas e na qual vigoram o imperativo do gozo constante e da felicidade compulsória, o corpo humano é desprezado. Ele é condenado por ser impuro em um novo sentido: imperfeito e finito; orgânico, demasiadamente orgânico... e, portanto, fatalmente condenado à decomposição e à obsolescência. 
A acusação de impureza aplicada ao corpo humano não é uma novidade histórica. No entanto, apesar das evidentes semelhanças, a poluição atual não é idêntica à que vigorou em outros períodos da civilização ocidental. Em um mundo secularizado e completamente atravessado pela lógica do mercado e pelos dispositivos tecnocientíficos, é inconcebível qualquer sacrifício em nome de valores transcendentes. Ao contrário, o novo ascetismo mantém uma relação complexa e aparentemente contraditória com o mercado e com as práticas hedonistas ligadas ao consumo, dando à luz a uma série de rebentos característicos da era atual: da prolífica bibliografia de auto-ajuda a toda a farmacopéia antioxidante, envolvendo uma miríade de produtos e serviços que cobrem dos suplementos vitamínicos às cirurgias plásticas, das academias de ioga aos spas e aos personal trainers. O novo receituário da expurgação compreende, assim, das dietas à musculação, toda uma série de práticas acéticas de novo cunho, que exigem dos sujeitos uma disciplina férrea e uma intensa série de sacrifícios - além de tempo e dinheiro, dois fatores primordiais na presente formação histórica. Tudo isso na procura de uma certa pureza.

Mas de que pureza se trata? O objetivo explícito de tais rituais não é alcançar a excelência pública (como na polis grega) ou a comunhão com Deus (como nas experiências místicas), pois a intenção não consiste em se libertar dos caprichos do corpo para dominar a si mesmo e aos outros, e tampouco em transcender a vida mundana para atingir outras alturas. ${ }^{22}$ Ao contrário, a nova moralização das práticas corporais tem metas bem mais prosaicas: vencer no mercado das aparências, fazer sucesso, ganhar eficiência e efetuar uma boa performance física e sobretudo visual; enfim, todos valores mercadológicos. O termo fitness, nesse sentido, revela sua origem etimológica em língua inglesa e se mostra como uma palavra de ordem que incita a se adequar ao modelo hegemônico.

\section{Imagens da pureza (digital) e a rejei- ção da materialidade orgânica}

Escolhendo-a como emblema da propensão de sua esposa ao pecado, à miséria, à deterioração e à morte, a sombria imaginação de Aylmer não demorou em converter a mancha de nascença num objeto de espanto, origem de um desassossego e um horror maiores do que todos os deleites que a beleza de Georgina poderia ter nele suscitado... ${ }^{23}$

Esse modelo corporal fat-free que está se tornando hegemônico nas culturas aglutinadas pelo mercado global parece se aproximar, cada vez mais, de um ideal de pureza digital. Vale lembrar, por exemplo, que programas de edição gráfica - como o PhotoShop e outras ferramentas do gênero - desempenham um papel fundamental na construção das imagens publicitárias e midiáticas que expõem "corpos belos", e que constituem uma poderosa fonte de imagens corporais no mundo contemporâneo. Todos os "defeitos" e outros detalhes demasiadamente orgânicos presentes nos corpos fotografados são eliminados, retocados ou corrigidos na tela do computador, utilizando esses instrumentos de software. Assim, as imagens expostas no mercado de produtos, serviços e aparências aderem a um ideal de pureza digital, longe de toda imperfeição toscamente analógica e de toda viscosidade exageradamente orgânica.

Esse modelo digitalizado - e, sobretudo, digitalizante - hoje extrapola as telas para impregnar os corpos e as subjetividades, pois as imagens assim editadas se convertem em objetos de desejo a serem reproduzidos na própria carne virtualizada. ${ }^{24}$ E, como ocorre com os transtornos dismórficos, o bisturi digital também costuma escolher os jovens corpos femininos como seu alvo predileto - uma coincidência que, certamente, não convém nomear com a palavra acaso. Mas há um detalhe particularmente interessante nas desmesuradas ambições 
destas "bonecas digitais": elas pretendem abandonar todo e qualquer vínculo com a materialidade, diferentemente do que ocorrera com as suas ancestrais, aquelas andróides (ou ginóides) imaginadas entre os séculos XVIII e XX, personagens decalcadas no modelo da máquina analógica que vigorou no auge da sociedade industrial - como as pioneiras Olímpia de Hoffmann e Eva Futura de L'Isle Adam, ou até mesmo a famosa robô do filme Metrópolis. ${ }^{25}$ As novas versões da feminilidade tecnologizada superam claramente esses antigos modelos, pois agora não é apenas a materialidade orgânica que se vê rejeitada: as reluzentes damas de bits de hoje em dia dispensam também o hardware mecânico para assumirem seus corpos de puro software; ou melhor: de pura imagem imaterial.

Numa redefinição radical da sensualidade, trata-se de um corpo-ícone descarnado e bidimensional (embora com polidos "efeitos 3D"), desenhado exclusivamente para ser exibido e observado; isto é, consumido apenas visualmente. Nessa curiosa dissipação da matéria que subjaz aos novos modelos corporais, somente um dos cinco sentidos perceptuais é privilegiado - significativamente, aquele que opera melhor com a distância: a visão. Munido de toda uma tradição "objetivante" que o legitima como um mecanismo detentor da "verda$\mathrm{de}^{\prime \prime}$, o olhar monopoliza a sinestesia e acaba empobrecendo toda a riqueza sensorial na apreciação da beleza, da espessura e da potência dos corpos.

Em 1999, uma das principais agências de modelos do mundo, a Elite, lançou um produto e um pacote de serviços inovadores: a modelo Webbie Tookay, uma morena digital que seria a primeira integrante de uma equipe formada por versões em bits de representantes de todos os tipos femininos bem cotados no mercado das aparências. "Estamos lançando um novo conceito de beleza para o próximo milênio", declarou o diretor da agência. ${ }^{26}$ Atualmente está sendo organizado um concurso para escolher a Miss Mundo Digital, com a participação de modelos 3D (todas femininas e digitais) criadas por programadores de software de diversos países (todos masculinos e analógicos). De acordo com o coordenador do evento, a meta é buscar "um ideal de beleza contemporâneo através da realidade virtual". ${ }^{27}$ A proposta evoca a figura de uma pioneira: Lara Croft, famosa personagem do jogo de computador Tomb Raider, que após se converter em "símbolo sexual" em sua versão virtual, chegou a ser interpretada no cinema por uma atriz real - porém, como já é de praxe, tanto no filme como nas fotografias de divulgação, as imagens do corpo e do rosto da protagonista foram convenientemente retocadas e "aperfeiçoadas" com artimanhas digitais. Ecoando esses fenômenos, a revista Playboy anunciou que irá fazer algo até agora inédito: pela primeira vez na história, em sua edição de outubro de 2004, a emblemática revista publicará uma série de ensaios eróticos com imagens de várias "divas virtuais", entre as quais se destaca a heroína do jogo Bloodrayne. ${ }^{28}$

Novidades desse tipo parecem ensaiar os primeiros passos de uma fantasia coletiva que propõe modelos hiperrealistas. Ou seja: mulheres especialmente planejadas para serem belas e visualmente atraentes, constituindo modelos quase impossíveis de tão "perfeitas" e com evidentes "vantagens" se comparadas com suas colegas tradicionais e analógicas, aquelas que são produtos do acaso biológico e que se compõem da matéria mais vulgar e mundana: átomos, ossos, carne e vísceras - entre outros abjetos e partes malditas. Assim, os novos vetores do biopoder desdobram seus imperativos: os corpos reais devem sofrer para estarem à altura desses modelos hiperreais.

\section{- corpo light: jejuns purificadores e a luz como alimento}

Georgiana não deixou de observar que seus mais esplêndidos sucessos eram quase sempre fracassos se comparados com o ideal ao qual aspiravam. ${ }^{29}$ 
Esse ódio à flacidez e à gordura, todo esse desconforto com relação à materialidade orgânica do corpo humano, chega a ter algumas ressonâncias insólitas - que, no entanto, podem ser interessantes para iluminar as hipóteses aqui propostas, pois se apresentam como sintomas de uma importante tendência atual. Uma delas é aludida em uma notícia publicada originalmente no jornal The New York Times sob o título “O jejum prolongado vira moda em um setor da classe média alta". O artigo se refere a um novo hábito tido por salutar, explicado da seguinte maneira: "deixar de comer alguns dias ajuda a purificar o corpo contaminado pela comida-lixo e a mente fustigada pelo estresse". Uma nutricionista citada no texto assevera que o jejum conduz a uma depuração completa do corpo: "permite que o sistema digestivo descanse e dá tempo para que as enzimas se dediquem a curar os órgãos, a rejuvenescer as células e a voltar o tempo para trás, além de fazer com que a agulha da balança retroceda". Mas a reportagem cita também as vozes dissonantes de alguns profissionais da área de saúde, que alertam contra os perigos envolvidos nessa retórica da pureza corporal e esclarecem que "nossos corpos não estão sujos". Uma psicóloga especializada em desordens alimentares, por sua vez, afirma que "a mera idéia de que seja possível superar as necessidades corporais e a estimulação ambiental à comida transmite uma sensação de pureza e de virtude". A estranha moda talvez não seja tão estranha assim: ela tem "motivos óbvios", conclui o artigo, porque hoje presta-se cada vez mais atenção à dieta e à saúde; "muitas pessoas reagem com força diante da atitude insalubre da sociedade com relação aos alimentos, pois temem o impacto da comida-lixo em suas vidas e o fantasma da obesidade, que vai crescendo com os anos". ${ }^{30}$

Trata-se de uma releitura paradoxal - e, sem dúvida, carregada de feroz ironia - da famosa música de Chico Buarque, Brejo da Cruz (1984). Neste caso, porém, a novidade de "se alimentar de luz" não é mais um atributo exclusivo dos pobres abjetos esfomeados, mas também dos membros do extremo oposto da pirâmide social - aqueles que desesperadamente desejam fugir de uma nova ameaça de abjeção: a gordura. Curiosamente, esses extremos parecem se encontrar hoje em dia, conformando uma interessante paródia do capitalismo contemporâneo como uma fabulosa máquina de produção de excesso e de falta ao mesmo tempo. Assim, perfeitamente delimitados em termos sócio-culturais e econômicos, o fantasma da fome e o fantasma da gordura assombram os sujeitos contemporâneos de modos bem diversos e até mesmo contraditórios - e, talvez, provavelmente, também complementares.

O fenômeno é ilustrado de maneira incrivelmente literal pelo "casal que se alimenta de luz", uma notícia que foi bastante divulgada pela mídia em anos recentes, demonstrando uma capacidade singular para impregnar o imaginário social. Parece uma fábula, mas não é: a brasileira Evelyn Levy Torrence, de 40 anos de idade, e seu marido Steve Torrence, norte-americano, contam a quem quiser ouvi-los que perderam "o vício de comer". Ambos juram não ter ingerido absolutamente nenhum alimento desde 1999, diminuindo também drasticamente o consumo de líquidos. "Trata-se de um processo de purificação orgânica, como uma cura de desintoxicação", explica o casal, que mora na Florida (EUA) e integra uma agrupação internacional composta por milhares de pessoas dedicadas a seguir os ensinamentos da australiana Jasmuheen, autora do livro Viver da Luz - que também afirma praticar esse "estilo de vida" desde 1993. ${ }^{31}$ De acordo com esta perspectiva, o hábito de comer não constitui uma necessidade biológica do organismo humano mas um "vício mortal", que se pode (e se deveria) perder. "Só comemos porque estamos viciados em comida, uma dependência causadora de $90 \%$ das doenças da humanidade". ${ }^{32}$

É interessante comparar o site desse etéreo casal na Web - intitulado Vivendo da $L u z{ }^{33}$ com toda sua eloqüência neo-gnóstica 
de espiritualização e superação triunfante dos limites corporais - com os weblogs que aderem ao movimento conhecido como ProAnorexia, nos quais adolescentes vítimas desse transtorno dismórfico confirmam sua opção por esses "estilos de vida" e defendem seus "direitos de não comer". As autoras desses blogs publicam fotografias delas próprias e de suas heroínas que lhes proporcionam thinspiration ou "inspiração para emagrecer" (como a modelo Kate Moss e a atriz Calista Flockhart), trocam informações e truques para perder peso e glorificam a capacidade de controlar o próprio corpo. Uma delas, por exemplo, desabafa assim: "Tenho que tirar essa banha que está no meu corpo, tenho que conseguir e vou conseguir; nós todas vamos ser magras e lindas, vamos ser perfeitas; unidas, temos muito mais força para combater a comida!". ${ }^{34}$ Outro desses sites se apresenta assim: "A anorexia não é uma doença e nem um jogo; é uma habilidade, aperfeiçoada somente por umas poucas pessoas: os escolhidos, os puros, os impecáveis". ${ }^{35} \mathrm{~A}$ retórica, como se vê, é exatamente idêntica à utilizada pelo casal que "se alimenta de luz". O contraste entre ambas as estratégias purificadoras, porém, é atroz: toda a pulcra imaterialidade, a pureza não-orgânica e a cândida luminosidade do primeiro caso se estilhaçam neste outro. Em contraposição àquela leveza supostamente incorpórea revestida com um verniz de irrealismo zen bem ao gosto midiático, aqui, corpos evidentemente mortificados protagonizam um drama marcado pela teimosia da carne e pelo intenso sofrimento psicofísico dessas jovens que desejam dela se livrar.

Mas ambas as estratégias estão aparentadas e sugerem a existência de uma raiz comum; uma atmosfera que as excede e as engloba, um certo clima sócio-cultural, econômico e político que as acolhe e as torna possíveis. Não constituem, certamente, os únicos exemplos de "artistas da fome" que hoje proliferam, genuínos fundamentalistas da norma em meio à crescente cultura do risco. ${ }^{36} \mathrm{Se}$, sob o amparo de uma certa cultura new age de inspiração orientalista, a luz do sol é apresentada como capaz de nutrir os corpos humanos e mantê-los vivos - além de mais belos e sadios - sem a necessidade de "poluí-los" com alimentos grosseiramente materiais, uma proposta semelhante emana de outro campo fundamental da cultura contemporânea: a tecnociência. Trata-se da invenção de "comida digital", alimentos compostos apenas de software, substâncias imateriais escritas em código informático. Esse sonho já foi apresentado em diversas ocasiões na ficção-científica, como por exemplo na primeira parte da trilogia Matrix - numa cena daquele filme, diante de um suculento prato de comida prestes a ser devorado, um personagem explica a outro que tanto o prato como os alimentos que ele contém na realidade não existem, pois tratar-se-ia de mera informação; ou seja, instruções de software capazes de disparar no cérebro todos os efeitos sensoriais que uma versão real do alimento produziria materialmente.

Mais uma vez, a tecnociência se propõe a realizar os sonhos da ficção-científica que povoam o imaginário contemporâneo, como anunciou o periódico Technology Research News em agosto de 2003: "pesquisadores da Universidade Tsukuba elaboraram um simulador de comida que emula os sons, as texturas e os sabores associados ao ato de comer comida real". O aparelho consiste numa complexa interface para morder, um alto-falante que acrescenta o som (das mordidas, da mastigação e do ato de tragar), um vaporizador que espalha cheiros e aromas, e um dispositivo que combina os elementos básicos que definem o sabor (doce, azedo, amargo, salgado), todos captados com sensores específicos a partir de alimentos reais. ${ }^{37} \mathrm{O}$ que se come, porém, é nada. Por tal motivo, o curioso e ainda precário artefato parece traduzir um grande sonho da subjetividade contemporânea: conservar o prazer sensorial de consumir certos alimentos, mas sem acrescentar matéria alguma ao corpo que "come". Pois também neste caso ingere-se apenas a mais 
pura luz - aqui, entretanto, ela é literalmente digital.

\section{A moral da comida impura: último capífulo de uma longa história}

A mancha fatal segurava o mistério da vida; era o laço por meio do qual um espírito angélico permanecera unido a um corpo mortal. ${ }^{38}$

Que estranha forma da pureza é essa que se impõe hoje em dia, em um mundo supostamente comandado pelas mais prosaicas e prazerosas leis do hedonismo, da gula consumista e da festa das sensações corporais? Em suas instigantes reflexões sobre o "mal-estar na pós-modernidade", Zygmunt Bauman lembra dos ideais de ordem, limpeza, beleza e pureza que regiram a civilização moderna, e que levaram Sigmund Freud a enunciar a dinâmica do princípio de liberdade individual sendo sacrificado em nome da segurança, como foi belamente explicitado em seu famoso ensaio O mal-estar na cultura. Mas, como bem mostra Bauman em seus próprios textos, isso ocorreu no distante ano de 1930, e de lá para cá muitas coisas mudaram. Essa lógica que vigorou na Modernidade e que Freud elucidou de maneira magistral, hoje teria se invertido. Agora os indivíduos sacrificam boa parte da sua segurança (outrora medida em termos de ordem, limpeza, beleza e pureza) em nome de um valor ainda mais supremo e desejado: a liberdade. Com a troca de prioridades, porém, desdobra-se um interessante jogo paradoxal: "quando é a vez da segurança ser sacrificada no templo da liberdade individual, ela furta muito do brilho da antiga vítima". ${ }^{39} \mathrm{E}$ eis que, como sempre é mais necessário e prezado aquilo que mais falta, hoje, no suposto império das liberdades individuais sem limites e do hedonismo radical, estaria em alta nada menos do que a segurança, com todo seu séqüito saudosista de velhas purezas.

Mas o que seria mesmo essa pureza que hoje renasce com tanto ímpeto? Tal con- ceito pode ser formulado como uma certa visão do mundo, um equivalente da ordem. Nesse sentido, o oposto do puro (isto é, o impuro, o sujo, a poluição, enfim, o abjeto) equivale àqueles elementos que desafiam uma certa ordem (isto é, um ambiente definido como regular e estável, um meio confiável). A busca da pureza, portanto, consiste em se livrar desses elementos perturbadores da ordem: as impurezas. A antropóloga Mary Douglas é uma das referências obrigatórias quando se trata deste assunto. Em seu famoso livro Pureza e Perigo, a autora também associa as impurezas à desordem, e encontra nesses mecanismos de busca da pureza um padrão universal. Mas a autora também revela um detalhe importante: não existe a sujeira absoluta. As coisas são puras ou impuras conforme as definições de quem as observa; isto é, de acordo com uma certa cosmologia. A busca da pureza, portanto, implica a criação de uma ordem, a adaptação do mundo a uma idéia. Purificar não é uma atividade negativa, de eliminação da sujeira, mas uma atividade positiva: deflagra a luta por atingir um ideal. ${ }^{40} \mathrm{E}$ cada modelo de pureza tem seu próprio modelo da sujeira que precisa ser eliminada.

Não é difícil intuir o forte peso moral que a idéia de pureza carrega, com suas inevitáveis conotações do bom e do belo, em franca oposição a seus contrários certamente indesejáveis. E, visto que para que existam os puros devem existir necessariamente os impuros, ressurge aqui outra categoria problemática: os escolhidos, ou seja, aqueles que se encontram mais perto da pureza do que todos os demais - os outros. No contexto da sociedade dos riscos, o impuro é portador de uma enorme potência negativa, pois ele é capaz de alterar a ordem e a tão prezada segurança, poluindo o mundo com uma ação tão real como simbólica. ${ }^{41}$ Assim, cabe deduzir que certos alimentos e certas práticas ou "estilos de vida" tidos como perniciosos, hoje se apresentam como agentes poluidores da ordem. E ocupam um papel tão central na nossa cultura porque eles ameaçam - colocam em risco - nada menos 
do que a tão valorizada pureza das formas do "corpo bom", o último grande ideal que todos os membros da sociedade ocidental parecem almejar. Para combater tais impurezas, portanto, entende-se que nenhum sacrifício deva ser poupado.

Mas a alimentação é uma necessidade vital do corpo humano; isto significa que a ingestão regular de alimentos constitui um requisito fundamental para manter o organismo vivo. Apesar da obviedade de uma frase como a anterior, ela precisa ser formulada à luz das tendências "virtualizantes" comentados nas páginas precedentes, que disseminam todo um leque de novas crenças e práticas alimentares com vistas a controlar algo cada vez mais importante e cada vez mais difícil de ser realmente controlado: a aparência do corpo, como uma imagem que deve ser sempre bela e pura. A conotação moral - e, portanto, política - desses processos é evidente.

Apesar da novidade deste fenômeno, vale a pena esboçar aqui uma breve genealogia dos azedos vínculos entre comida e moralidade. Longe de serem específicos da nossa formação histórica, tais nexos estão (e sempre estiveram) presentes em todas as culturas, originando uma série de regras de comportamento e um conjunto de proibições com relação aos alimentos. Desde que exista algum grau de escolha do que se pode comer - incluindo, é claro, a possibilidade de não comer nada - sempre será possível efetuar a escolha certa ou a errada, de acordo com as estipulações de cada universo simbólico. $\mathrm{Na}$ sociedade ocidental, por exemplo, a história de tais práticas é longa e densa. ${ }^{42} \mathrm{O}$ pecado, o jejum, o luxo, o erotismo, a abstinência, o prazer, a saúde, a gula, a moderação... é imensa a lista de valores que podem temperar os pratos servidos nas mais diversas mesas.

Inclusive hoje em dia, o peso moral vinculado aos alimentos exala uma variedade de valores, entre os quais é impossível ignorar a distinção social e o hedonismo. Os que revelam a potência mais inusitada, entretanto, são aqueles ligados a seus efeitos potencialmente poluidores da imagem corporal; mais do que nada, temem-se os eventuais impactos dos alimentos consumidos na aparência de quem come. Essa ênfase na repercussão visual da matéria "proibida" que se ingere constitui, certamente, uma novidade histórica. Outra novidade é o nível de importância social que tem envolvido o tema, saindo de um sectarismo religioso ou ideológico sempre restrito a uns poucos "extremistas" ou "fanáticos", para atingir progressivamente todas as camadas da população global. Um processo que, ainda em seus primórdios, levou a revista Psicology Today a enunciar uma asseveração que talvez parecia exagerada ou - no mínimo - visionária em 1971, mas que agora desperta poucas dúvidas: "a alimentação está substituindo o sexo como objeto de culpabilidade". ${ }^{43}$

\section{Agruras da perfeição imaterial (ou os gordos custos da felicidade lipo- aspirada)}

Apagadas da bochecha as últimas nuanças da mancha de nascença (único indício de imperfeição humana), o derradeiro suspiro da jovem, já perfeita, misturou-se com o ar; após permanecer alguns instantes ao lado do seu marido, a alma de Georgiana empreendeu seu vôo celestial. ${ }^{44}$

As epígrafes que ilustram este texto pretendem mostrar até que ponto as coisas mudaram - apesar das evidentes continuidades - desde aquele remoto ano de 1843 em que o escritor norte-americano Nathaniel Hawthorne dera a conhecer seu conto The Birthmark. Hoje não surpreende a estranha temática que 160 anos atrás inspirara este aterrorizante conto gótico sobre uma "mulher enlouquecida", capaz de qualquer coisa por apagar uma pequena marca que sujava seu belo rosto.

A intenção explícita do relato, porém, é a de denunciar os desvarios e as cegas ambições do marido da jovem, um cientista 
alucinado, como uma alegoria dos perigos aos quais podia conduzir a audaciosa ciência da época. Um temor, aliás, bastante espalhado naqueles longínquos inícios do século XIX, e perfeitamente encarnado em outro personagem fictício quase contemporâneo da desventurada Georgiana e seu inefável esposo: o Dr. Victor Frankenstein. ${ }^{45}$ Outro exemplo é um terceiro médico gótico, igualmente desvairado e ambicioso: o Dr. Spalanzani, personagem do conto $O$ homem de areia, do alemão E.T.A. Hoffmann, em cujas páginas - redigidas em 1816 - criara aquela outra humanóide fatal chamada Olímpia. ${ }^{46}$

Logo no subtítulo do seu famoso livro publicado em 1818, a própria autora de Frankenstein, a inglesa Mary Shelley, resolveu definir seu célebre doutor fictício como O moderno Prometeu. Do mesmo modo, seus colegas Aylmer e Spalanzani também poderiam assumir o papel do mítico titã grego - aquele que foi duramente punido pelos deuses por ter desafiado as limitações humanas usurpando as prerrogativas divinas: Prometeu.

Entretanto, já há tempos que os deuses abandonaram a cena. Hoje, quase dois séculos depois dessas fantásticas invenções, os riscos passaram a ser meramente terrenos e individuais - e, conforme nos é dito, em certos casos, a decisão de corrê-los pode até valer a pena. Afinal, todos temos (ou deveríamos ter) um fundamental direito ao risco. A responsabilidade é de cada um, e todos podemos decidir livremente se desejamos (ou não) livrar-nos - nem que seja provisoriamente - da impureza corporal que nos é teimosamente inerente.

Assim, todos podemos (ou talvez devamos) escolher o sacrifício bio-ascético mais propício em cada caso, avaliando os riscos e os benefícios a fim de atingir a "perfeição" que os deuses insistem em nos negar, como também negaram à belíssima porém maculada Georgiana de Hawthorne. Por isso, nos complexos tempos atuais, a tecnociência parece alentar o surgimento de outras figuras míticas, cada vez mais distantes do castiga- do Prometeu (afinal, um titã desobediente e portanto culpável) e mais próximas do destemido Fausto (afinal, um homem com ambições demasiadamente divinas). ${ }^{47} \mathrm{Nesta}$ passagem de um arquétipo para outro, não é difícil vislumbrar nos perfis desses médicos góticos da primeira metade do século XIX, Frankenstein, Aylmer e Spalanzani, inquietantes ecos ancestrais de uma espécie hoje triunfante: a dos cirurgiões plásticos. Como versões contemporâneas do clássico Pigmaleão, longe de protagonizarem dramas góticos com finais terríveis, esses profissionais da medicina estética se orgulham da sua primorosa coleção de happy ends: afinal, com seus afiados bisturis, eles costumam modelar os melhores exemplares da beleza feminina que hoje brilham nas telas do mundo.

É por isso que diante de nossos olhos do século XXI, tão ávidos como saturados, a tragédia protagonizada por Aylmer e Georgiana não parece mais "desvairada" ou exageradamente alegórica, como deve ter se apresentado aos receosos leitores da primeira metade do século XIX. Hoje, ao contrário, tais inquietações fazem parte do cotidiano e impregnam nosso imaginário até o ponto de coagularem no senso-comum. Basta evocar aqui, para finalizar, apenas dois exemplos atualíssimos, que retomam essa antiga temática gótica para recriá-la em cenários bem contemporâneos.

Por um lado, o auge mundial dos reality-shows cujos protagonistas recorrem às mais diversas técnicas de aperfeiçoamento físico, especialmente a complicadas e custosas cirurgias plásticas, enfrentando sérios riscos, dores e sacrifícios para atingir uma certa pureza na sua própria imagem corporal; isto é, uma proximidade do modelo ideal cada vez mais inatingível.

Por outro lado, cabe mencionar o caso do jovem músico Marcus Menna, integrante do grupo pop LS Jack, que com 27 anos de idade e um aspecto físico que poderia ser considerado "normal", entrou em coma após se submeter a uma cirurgia de lipoaspiração no abdômen em uma clínica do 
Rio de Janeiro. Menna fazia sucesso com sua banda, era "felizmente casado" e tinha um filho de nove meses, porém "não estava satisfeito com o próprio corpo" e resolveu fazer a intervenção cirúrgica "por uma questão de auto-estima". ${ }^{48}$ Uma alegoria, talvez, do mais recente horror neogótico ?

Ouviu-se novamente uma bronca gargaIhada! Assim debocha sempre a crua fatalidade da terra em seu triunfo invariável sobre a essência imortal... ${ }^{49}$

\section{Notas}

1 HAWTHORNE, Nathaniel. "La Mancha de Nacimiento" (1843). In: BERGA, Miquel (Org). Cinco mujeres locas. Cuentos góticos de la literatura norteamericana. Barcelona: $\mathrm{Ed}$. Lumen, 2001. p. 24.

2 Atualmente, $65 \%$ dos adultos dos Estados Unidos estão excedidos de peso; essa proporção equivale a 120 milhões de pessoas, enquanto 59 milhões de cidadãos norte-americanos são considerados obesos. 0 aumento foi vertiginoso na última década, e os números continuam engordando. (Science, 7/02/2003. http://www.sciencemag.org). Diversas pesquisas indicam, também, que o problema está aumentando nos países menos desenvolvidos, especialmente entre as crianças: $35 \%$ da população infantil mundial é afetada pelo sobrepeso ou pela obesidade. (La Nación, Buenos Aires, 22/08/2004. "La obesidad, problema en uno de cada 3 niños". http://www.lanacion.com.ar/629360).

3 Folha de São Paulo, 29/05/2004.

4 Além da miríade de pesquisas e descobertas tecnocientíficas divulgadas diariamente na mídia, basta mencionar um par de exemplos algo alegóricos porém bastante explícitos: na contramão dos programas Fome Zero nacionais e internacionais que constituem uma das principais bandeiras discursivas do atual presidente do Brasil, a Organização Mundial de Saúde (OMS) acaba de sancionar a Estratégia Global sobre Dieta, Atividade Física e Saúde, um "projeto para deter a obesidade no planeta". Fortemente apoiado pelos Estados Unidos e pelo lobby das indústrias alimentícias, o projeto foi aprovado pelos 192 representantes nacionais que integram a organização, após superar uma polêmica levantada pela oposição dos países produtores de açúcar - significativamente liderados por Cuba. Cf. "OMS espera aprovar plano antiobesidade na próxima semana". Reuters, 14/05/2004; e "Aprovado plano mundial de combate à obesidade". Reuters, 22/05/2004.

5 HAWTHORNE, op. cit. p. 27-28.

6 Cf. BEZERRA Jr., Benilton. 0 ocaso da interioridade. In: PLASTINO, C. (Org.). Transgressões. Rio de Janeiro: Contracapa, 2002.

\section{HAWTHORNE, op. cit. p. 42.}

8 Cf. FOUCAULT, Michel. História da Sexualidade I: A vontade de saber. Rio de Janeiro: Graal, 1980; FOUCAULT, Michel. Em defesa da sociedade. São Paulo: Martins Fontes, 2000.

9 A separação entre ambos os grupos sociais (os que contam e os que não contam na sociedade contemporânea) parece exigir uma elaboração mais complexa do que aquela expressa por Ulrich Beck como sendo, basicamente, uma diferença entre "primeiro mundo" e "terceiro mundo". Uma tentativa mais precisa (em sua admitida imprecisão) é a que Zygmunt Bauman efetua entre "turistas" e "vagabundos", por exemplo, ambos os tipos entremeados nas sociedades ricas e pobres de um planeta cada vez mais globalizado, como categorias que se misturam no dia a dia das grandes cidades e que possuem limites difusos, com o risco permanente de qualquer uma delas se converter subitamente em seu oposto. Cf. BAUMAN, Zygmunt. Globalização: As conseqüências humanas. Rio de Janeiro: Jorge Zahar, 1999.

10 BECK, Ulrich. Risk Society: Towards a New Modernity. Londres: Sage, 2002. p. 20.

11 Sobre estas e outras questões relacionadas com a noção de risco, ver os estudos de Paulo Vaz, tais como: VAZ, Paulo. Corpo e risco. In: VILLAÇA, N.; GÓES, F; KOSOVSKI, E. (org.). Que corpo é esse? Rio de Janeiro: Mauad, 1999; e VAZ, Paulo. O corpo-propriedade. In: NETO, Antonio Fausto; PINTO, Milton (org.), Mídia e Cultura. Rio de Janeiro: Diadorim, 1997.

12 DUARTE, Sara. "Guerra à fast-food". Época, 16/08/2004. http://revistaepoca.globo.com/Epoca/0,6993,EPT794005$\underline{1664-1,00 . \mathrm{html}}$.

13 Cf. SENNETT, Richard. 0 declínio do homem público: Tiranias da intimidade. São Paulo: Companhia das Letras, 1999. Cf. também BAUMAN, Zygmunt. Em busca da politi- 
ca. Rio de Janeiro: Jorge Zahar Editor, 2000.

14 Cf. TAYLOR, Charles. As fontes do self: A construção da identidade moderna. São Paulo: Ed. Loyola, 1997.

15 Cf. WEBER, Max. La ética protestante y el espíritu del capitalismo. Buenos Aires: Ed. Andrómeda, 2004.

16 KAFKA, Franz. A construção. São Paulo: Brasiliense, 1984.

17 HAWTHORNE, op. cit. p. 24.

18 A bulimia se caracteriza pela ingestão compulsiva de grandes quantidades de alimentos e a conseqüente provocação voluntária de vômitos, com a intenção de expulsá-los do organismo; já a vigorexia é a obsessão pelo desenvolvimento de um corpo musculoso; e a ortorexia designa a compulsão ao consumo de alimentos "naturais" e "saudáveis".

19 WEISS, Gail. The abject borders of the body image. In: WEISS, Gail e FERN HABER, Honi (Orgs.) Perspectives on Embodiment: The Intersections of Nature and Culture, London and New York, Routledge, 1999.

20 Para um exame mais aprofundado do conceito de "corpo vivo", ver MERLEAU-PONTY, Maurice. Fenomenologia da Percepção. São Paulo: Martins Fontes, 2002.

21 HAWTHORNE, op. cit. p. 43.

22 Cf. ORTEGA, Francisco. Da ascese à bio-ascese, ou do corpo submetido à submissão ao corpo. In: RAGO, M.; ORLANDI, Luiz e VEIGA-NETO, Alfredo (Orgs.). Imagens de Foucault e Deleuze: ressonâncias nietzchianas. Rio de Janeiro: DP\&A, 2002.

23 HAWTHORNE, op. cit. p. 24.

24 Cf. SIBILIA, Paula; RODRIGUES, Carla. O carnaval da beleza globalizada (entrevista). No Mínimo. Rio de Janeiro, 16/02/2004. <http://www.nominimo.com.br>.

25 HOFFMANN, E.T.A. 0 homem de areia. Contos sinistros. São Paulo: Max Limonad, 1987; VILLIERS DE L’ISLEADAM, Auguste. A Eva Futura, São Paulo: Edusp, 2001; LANG, Fritz. Metrópolis. Alemanha, 1927.

26 Cf. John CASABLANCAS: http://www.illusion2k.com. 27 Miss Digital World: http://www.missdigitalworld.com.
28 REZENDE, Emerson. "Playboy fará ensaio com personagem de Bloodrayne". Yahoo! Notícias Brasil, 24/08/2004. http:// br.news.yahoo.com/040824/7/mkmr.html.

29 HAWTHORNE, op. cit. p. 39.

30 GRIGORIADIS, Vanessa. "El ayuno prolongado se puso de moda en un sector de la clase media alta norteamericana". Clarín, Buenos Aires, 02/09/2003. http://old.clarin.com/ diario/2003/09/02/s-03701.htm.

31 JASMUHEEN, Viver da Luz. São Paulo: Ed. Aquariana, 2001. Mais informações em http://www.jasmuheen.com.

32 SANTOS FERREIRA, Paula. "Viver da Luz". A Capital. Lisboa, 7/09/2001.

33 Vivendo da Luz: http://www.vivendodaluz.com.

34 EPPRECHT, Catharina. "Grupos defendem anorexia e bulimia". Jornal do Brasil, Rio de Janeiro, 20/9/2004.

35 DOMINGO, Laura. "Centenares de 'webs' proanorexia animan a jóvenes a adelgazar". El Mundo, Madri, 15/9/2001. Convém esclarecer que sites deste tipo são constantemente banidos e retirados da Internet. No entanto, eles continuam a proliferar; basta digitar o termo "proanorexia" em um site de busca como o Google para se ter acesso a vários deles.

36 Cf. KAFKA, Franz. Un artista del hambre. In: BORGES, Jorge Luis (Org.). Kafka: El buitre. Buenos Aires: Ediciones Librería La Ciudad, 1979.

37 "Device Simulates Food". Technology Research News. 6/08/2003. http://www.technologyreview.com/articles/ $\underline{\mathrm{rnb} 080603 . \mathrm{asp}}$.

38 HAWTHORNE, op. cit. p. 47.

39 BAUMAN, Zygmunt. 0 mal-estar da pós-modernidade. Rio de Janeiro: Jorge Zahar Editor, 1998. p. 11.

40 DOUGLAS, Mary. Pureza e Perigo. São Paulo: Ed. Perspectiva, 1976.

41 Cf. HACKING, Ian. Risk and Dirt. In: ERICSON, Richard; DOYLE, Aaron (Orgs). Risk and Morality. Toronto: University of Toronto Press, 2003. p.22-47. 
42 Sobre as prédicas moralistas dos últimos dois séculos com relação aos hábitos alimentares, começando pelos puritanos norte-americanos, continuando com os socialistas utópicos e concluindo com as tendências contra-culturais dos anos 60 e 70, ver o interessante artigo de BELASCO, Warren. Food, morality and social reform. In: BRANDT, Allan; ROZIN, Paul (Orgs). Morality and health. London: Routledge, 1997. p. 185-200. Cf. também LEVENSTEIN, Harvey. Dietética contra gastronomia: tradições culinárias, santidade e saúde nos modelos de vida americanos. In: FLANDRIN, Jean Louis; MONTANARI, Massimo (Orgs.). História da alimentação. São Paulo: Estação Liberdade, 1998. p. $825-840$.

43 LEVENSTEIN, op. cit. p. 840.

44 HAWTHORNE, op. cit. p. 47.

45 SHELLEY, Mary. Frankenstein: 0 moderno Prometeu. São Paulo: Círculo do Livro, 1973.

46 HOFFMANN, E.T.A. $\mathrm{O}$ homem de areia. Contos sinistros. São Paulo: Max Limonad, 1987.

47 Para uma análise mais exaustiva da tensão fáustico-prometéica na história e na filosofia da tecnociência, vide MARTINS, Hermínio. Hegel, Texas e outros ensaios de teoria social. Lisboa: Edições Século XXI, 1996. Cf. também SIBILIA, Paula. O homem pós-orgânico: Corpo, subjetividade e tecnologias digitais. Rio de Janeiro: Relume Dumará, 2002.

48 ARAÚJO, Luís Edmundo. $\mathrm{O}$ drama do LS Jack. Istoé Gente, 7/7/2004. http://www.terra.com.br/istoegente.

49 HAWTHORNE, op. cit. p. 48. 